\title{
RESENHA: UM ENSAIO SOBRE GUERRAS HÍBRIDAS E O NOVO MEIO DE FAZER GUERRAS
}

\author{
Magno Felipe Sant'Ana de Oliveira' \\ Marcelo Robson da Costa Mota Junior ${ }^{2}$ \\ Roberta Gonzalez Bustamante ${ }^{3}$ \\ Yasmin Dourado Cavalcante ${ }^{4}$
}

\section{Introdução}

As Guerras Híbridas: das Revoluções Coloridas aos Golpes nos mostram um novo jeito de se observar o poder de influência de um âmbito social a ponto de haver uma tomada de poder. É válido citar também a origem dessa perspectiva pois mostra uma visão oriental sobre o mundo, com o autor Andrew Korybko, que carrega em seu perfil estudos voltados à geopolítica russa. A partir de uma perspectiva russa, não faltam críticas e pontos de atenção voltadas ao Estados Unidos, porém, levamos em consideração que qualquer Estado com um capital de investimento e influência social tem condições de agir de tal forma.

Dois pilares que precisam ser destrinchados durante a leitura são as "Revoluções Coloridas" e a "Guerra Não-Convencional". Nas "Revoluções Coloridas" é valorizada a ação de indivíduos dentro do país em que se pretende ser instaurado um possível golpe, que utilizam mecanismos acessíveis para ganhar uma maior mobilização que, independente da sua origem, são para realizar um golpe, ou para

\footnotetext{
1 Graduando em Relações Internacionais da Faculdade La Salle Manaus. E-mail: maagnofeliipe@hotmail.com.

2 Graduando em Relações Internacionais da Faculdade La Salle Manaus. E-mail: motamarcelojr@gmail.com.

3 Graduanda em Relações Internacionais da Faculdade La Salle Manaus. E-mail: robertagbustamante@hotmail.com.

4 Graduanda em Relações Internacionais da Faculdade La Salle Manaus. E-mail: yasmimdcavalcante@gmail.com
} 
alcançar o enfraquecimento do governo vigente. Com a "Guerra Não-Convencional", que é vista como um ataque final ao enfraquecido governo, trata-se de um ataque rápido e objetivo, sendo um recurso para a troca de regime por meio de grupos terroristas, guerrilhas, insurreição urbana, sabotagem e formas irregulares de se obter uma prática de guerra. Com o sucesso das práticas entre esses dois pilares, temos a aplicação do que seria uma Guerra Híbrida.

\section{Credencial do Autor}

Andrew Korybko é conselheiro do Institute for Strategic Studies and Predictions, além de analista político e jornalista atuando nas equipes de rádio e web da Sputnik News, onde apresenta semanalmente os programas Red Line e Context Countdown. Faz comentários técnicos ao vivo sobre os últimos acontecimentos da política interna e internacional (RT, Life News, Rússia). Suas especialidades técnicas são: Estratégias dos EUA na Eurásia, Revoluções Coloridas e Guerra Não Convencional, Política Externa Russa, Geopolítica da Energia e Estratégias de Integração da Eurásia, Multipolaridade, Competição entre Grandes Potências, e Estados Resistentes e Não Submissos.

\section{Resumo da Obra}

O livro inicia-se com uma introdução, e conduz-se aos capítulos que são diferenciados por quatro títulos: "Contextos Teóricos", "Aplicação das Revoluções Coloridas", "Aplicação da Guerra Não Convencional" e por último "A Ponte". Acompanhado de uma conclusão, anexos, bibliografia e agradecimentos sobre um questionamento de uma nova estratégia de legitimação para a soberania nacional.

A obra está fundamentada com diversas teorias de autores renomados em diversas áreas, desde a geopolítica a questões próprias de direito como, por exemplo, o início do primeiro capítulo apresenta como a geopolítica se tornou uma base para a formulação das políticas de cada Estado, evidenciando sua evolução desde Alfred Thayer Mahan, considerado o pai de geopolítica, até Zbigniew Brzezinski, que conseguiu combinar os ensinamentos geopolíticos às vistas da primazia estadunidense e criar a ideia dos Balcãs Eurasiáticos. A ideia apresentada para a intervenção estadunidense não é a de fomentar o separatismo, mas sim de que usar determinados recursos, usando de campanhas de sabotagem geopolítica indireta sob as aparências de movimentos "pró-democracia" ou confrontos civis apoiados por fora. 
A vantagem de tal abordagem é que não é preciso necessariamente derrubar um governo; é apenas necessário promover uma divisão na sociedade, criando incerteza em larga escala, e gerando assim o que o autor chama de caos periférico, o que é maximizado a fim de criar um fluxo caótico que desestabilize o Estado-alvo, e faz com que este seja obrigado a lidar com o problema, colocando-o assim em defensiva estratégica.

Dada a compreensão dos usos dos pontos geopolíticos, o autor apresentas teorias militares e explica à luz dessas teorias a atratividade da guerra indireta. Ele começa com William Lind que, em 1989, apresentou a ideia de guerras de quarta geração: estas seriam mais fluidas, descentralizadas e assimétricas, focando na guerra de informação e de operações psicológicas, podendo assim dizer que elas foram o alicerce das guerras hibridas, estando de pleno acordo com o funcionamento primeiro das revoluções coloridas.

Apresentadas as novas ideias de guerra, é descrita a teoria dos cinco anéis de John Warden, um coronel das forças americanas que conceitualizou a melhor maneira de atacar um inimigo. Esta teoria consistia na apresentação de cinco círculos concêntricos em graus de importâncias, sendo o menor e central o de maior importância, assim os cinco centros de gravidade que mantem uma força unida, são: liderança, bases do sistema, infraestrutura, população e mecanismos de combate. $\mathrm{Na}$ guerra convencional foca-se em atacar o ponto principal do círculo, a liderança, a fim de se desestruturar as outras estruturas que estão interligadas. Pode ser, porém, difícil encontrar uma brecha para atacar um alvo tão chamativo. Assim, nas revoluções coloridas estes anéis se tornam um pouco diferentes, havendo dois conjuntos de anéis diferentes para cada alvo: a sociedade e o indivíduo.

Assim, na sociedade, os anéis se apresentam, de fora para dentro, como população, mídia (internacional), elite nacional, forças armadas e liderança. A inovação da ideia se dá no uso do caos dirigido, usando de influência no anel mais externo (população) e passando-se a impressão de união para atingir diretamente o anel interno, driblando os demais. Se as forças armadas interferirem em favor do anel núcleo (liderança), este formula então o esquema para uma guerra não convencional. A elite é o terceiro anel, pois tem o poder de influência na mídia e nas populações, porém muitas vezes não tem tanto grau de influência com as forças armadas e com a liderança. Este cenário está mudando dado o alto grau de influência que algumas figuras públicas têm no setor privado, além de empresas transnacionais terem 
apresentado perante ao governo, juntamente com a mídia, graus variantes de influência.

O segundo alvo das revoluções coloridas são os indivíduos, e este tem por foco o recrutamento máximo destes indivíduos antes da desestabilização. Os anéis para este alvo variam de acordo com cada cultura e demografia etária, uma vez que o os valores variam, porém, geralmente os fatores giram em torno de país, religião, vizinhança, trabalho e família, sendo que o que muda são as colocações das posições de importância, umas vez que na maioria do Ocidente pode se colocar a família como ponto central das operações psicológicas a serem usadas neste ponto para um recrutamento. Assim, a guerra híbrida pode ser traduzida em uma parte assimétrica e singular da dominação de espectro total que pode ser mais bem resumida como a tentativa de administração do caos. Desta forma, mais uma vez, as tradicionais ocupações militares podem dar lugar a golpes e operações indiretas para troca de regime, que são muito mais econômicos e menos sensíveis do ponto de vista político.

Entramos em um meio multipolar, com um grande desenvolvimento de armamentos de destruição em massa, e em destaque podemos observar as grandes potências neste caminho: Estados como Estados Unidos e Rússia são o melhor exemplo no que diz respeito à paridade nuclear. Com essas mudanças, podemos observar que conflitos diretos se tornaram menos interessante para os países que economizariam mais, o que trouxe destaque para o que seria chamado de guerra indireta:

As mídias sociais e tecnologias afins substituirão as munições guiadas como armas de "ataque cirúrgico" da parte agressora, e as salas de bate-papo online e páginas no Facebook tornar-se-ão o novo "covil de militantes". Em vez de confrontar diretamente os alvos em seu próprio território, conflitos por procuração serão promovidos na vizinhança dos alvos para desestabilizar a periferia dos mesmos. As tradicionais ocupações militares podem dar lugar a golpes e operações indiretas para trocas de regime, que são muito mais econômicos e menos sensíveis do ponto de vista político". (Korybko, 2018, ORYBKO, p. 6).

Em a "Aplicação das Revoluções Coloridas", o autor define a estrutura teórica e estratégica que sustenta este fenômeno, tendo como início a difusão e disseminação de informação entre a população. Assim, segundo Bernays, não é necessário uma grande força para isso, basta posicionar pessoas em pontos estratégicos, a fim de influenciar subliminarmente pontos, orientando e influenciando massas a pensar de certa maneira, uma vez que várias das reviravoltas da política internacional trouxeram, naturalmente, consequências para a maneira como a política externa dos Estados passou a ser elaborada. E numa formulação contemporânea, 
considera-se a importância do papel das Organizações Internacionais como correntes de transmissão dos valores da sociedade internacional, sendo inclusive grande influenciadora de normas dos Estados. Além disso, aprofundou-se o uso das grandes corporações de redes sociais, a exemplo do ocorrido com o WhatsApp no Brasil, e a captura de instituições e autoridades judiciárias e policiais, além da mobilização de "formadores" de opinião.

Sendo uma nova maneira de agir dos Estados para que eles possam enfraquecer, mexendo na estabilização, movendo toda a estrutura de um meio que seja de dentro para fora, as Revoluções Coloridas fazem com que os civis se voltem contra o seu próprio Estado como uma maneira de enfraquecimento, ou, se houver uma oportunidade, de se instaurar um possível golpe. Então Korybko (2018) conceitua as Revoluções Coloridas como:

Um dos mais novos modelos para desestabilização de Estado. Elas permitem que atores externos manifestem negações plausíveis quando acusados de interferir ilegalmente nos assuntos domésticos de um Estado soberano, e a mobilização em massa do "poder do povo" faz delas altamente eficazes na ótica de mídia mundial. Além disso, o aglomerado de muitos civis protestando contra o governo também aumenta a pressão sobre o mesmo e limita suas opções para lidar com eficiência contra a desestabilização em andamento. Todas as Revoluções Coloridas seguem à risca o mesmo modelo, e entender a natureza dessa tática de desestabilização na prática permitirá elaborar contramedidas adequadas para se defender contra ela. (Korybko, 2018, p. 85).

Há toda uma estrutura para compreender os mecanismos de ação das Revoluções Coloridas, que seriam os fatores necessários para que se possam desenvolver suas atividades e cada um desses fatores podem ter ou não, suas subdivisões de atividades. Os fatores primários são: ideologia, financiamento, social, treinamento, Informação e mídia. Esses fatores têm a necessidade de dialogar entre si para que haja sucesso, e, de acordo com Korybko, eles funcionam como uma pirâmide.

Esses fatores estariam inclusos em um conjunto que forma um movimento, e junto a esse movimento haveriam outras variáveis: eles são o acontecimento e a infraestrutura física, então, para que ocorra a Revolução Colorida, é a capacidade de haver a junção majoritária entre as variáveis. O combustível que carrega o ponto central para iniciar a Revolução Colorida é a ideologia, que tem a capacidade de transformar tudo a sua volta e que sem ela tudo seria como um grande vazio, sem valor algum, como Korybko (2018) cita, por exemplo, na ideia de Democracia Liberal 
que carrega em grande parte do Ocidente, que seria uma maneira de "libertar" os Estados que são considerados como não democráticos.

A penetração ideológica em uma sociedade vai aos poucos ganhando corpo e implode fisicamente dentro do Estado em questão, guiada por um seguimento dos cidadãos do próprio Estado. Com isso, o Estado (e a sociedade como um todo) deve combater uma parte de si próprio que está "se levantando" contra o status quo, levando a um conflito de interesses a uma guerra civil social. Dependendo do nível de provocação a que os manifestantes pró-Liberal Democráticos dão início, bem como de casos de má administração do Estado no lidar com esse levante social, a guerra civil social pode uma hora ou outra acabar por tornar-se violenta e, em pouco tempo, tomar as aparências de uma guerra civil de verdade. (Korybko, 2018, p. 87).

É valido destacar que os agentes que procuram a transformação não podem nem notar que ela faz parte de um plano maior de um mandante superior, esse mandante podendo ser um Estado estrangeiro ou uma ONG, por exemplo, como o próprio Korybko (2018) cita, porém, todos são levados por uma campanha doutrinadora que tem a capacidade de desestabilizar, com o objetivo de mostrar que tudo isso é uma transformação "natural" e que toda a ação seria um meio de avançar como sociedade e a possibilidade de todas as regiões do mundo passarem pelo mesmo processo. No ponto social encontramos toda uma estrutura para conhecimento de como tudo isso decorre, desde o que seria a ponta da hierarquia, até a sua base estrutural, eles são definidos como Vanguarda, Assistentes e Simpatizantes.

A Vanguarda consiste em uma externalização da ideologia, são aqueles que tem contato direto com os financiadores de toda a ação para que haja a Revolução dentro do Estado-Alvo. Os Assistentes são a frente da organização, onde estão sempre alinhados em levar também a ideologia, porém, agem sempre com a intenção de em um momento fazer parte da Vanguarda, trabalham em processos administrativos da organização, e também, procurando fazer parte de processos seletivos de entrada. Por último, os Simpatizantes são a massa que faz toda a manifestação inchar e que acaba ganhando força e expressão quando se tem números grandes. Para se ter uma articulação bem feita, é preciso que haja um treinamento que é aplicado aos assistentes, eles aprendem como desenvolver os materiais de promoção das ideias, podendo utilizar as redes sociais como mecanismo, conduzir com sucesso toda a seleção para que haja um número grande de pessoas que se sintam pertencentes a mesma causa, além de aprender maneiras 
de arrecadar recursos para fazer que com tudo isso consiga rodar financeiramente bem.

O elemento de Informação, sempre sendo utilizado com base nas Mídias Sociais e Materiais de Propaganda, pode trabalhar em favor do Movimento, agindo por materiais físicos e virtuais. Korybko (2018, p. 93) define o papel da mídia como algo que "legitima a Ideologia do Movimento, dá-lhe as aparências de respeitável e solidifica a percepção de forte presença na sociedade, mais importante de tudo, ele tem objetivo primário de chegar ao público internacional”.

O Acontecimento é oficialmente iniciado depois deste evento, e é o momento de a organização utilizar de toda a energia canalizada para haver a Revolução, sendo considerado o chamado para ação. Esse acontecimento pode ocorrer como: fraude eleitoral, prisão de um líder da oposição, aprovação ou veto de uma lei controversa, sanção do governo contra a oposição ou imposição de lei marcial, declaração de envolvimento ou envolvimento em uma guerra impopular. Estes são apenas exemplos citados por Korybko (2018), porém, o que vai definir o poder de influência do acontecimento é como o público nota e percebe tudo isso, ou até mesmo como a mídia o narra. A Revolução Colorida é um forte mecanismo que age de várias formas simultaneamente, com toda uma estrutura muito bem organizada de ação, para que haja uma ação externa em um Estado-alvo, sem que haja muito gastos físicos e financeiros para que se consiga então interferir na política interna desse Estado, podendo culminar em um golpe.

No capítulo “Aplicação da Guerra Não Convencional',' o autor caracteriza esse tipo de guerra como um recurso para uma troca de regime, e que também pode significar a inclusão de grupos terroristas, guerrilhas, insurreição urbana, sabotagem e formas irregulares de se obter uma prática de guerra. E assim, caso seja bem sucedido, consegue-se alcançar o mesmo objetivo de uma intervenção direta, mas sem os gastos excessivos da utilização das Forças Armadas e dos métodos convencionais. Um notável exemplo do uso desta iniciativa estratégica é a ação dos Estados Unidos nos anos 80, durante a Doutrina Reagan, que apoiava insurreições anticomunistas em países como na Angola, Etiópia e Afeganistão.

A ideia de Guerra Não Convencional é um conceito criado nos Estados Unidos, e seriam maneiras de impulsionar um movimento para poder ter forças para enfraquecer ou derrubar um governo; ela passa longe de ser um mecanismo revolucionário. Este é um caminho para se tomar o controle de um Estado, que, desta 
forma, trariam benefícios para transações econômicas, políticas e até sociais, com um resultado positivo para os Estados Unidos.

O pilar deste conceito seria algo de responsabilidade total do governo norteamericano, reforçando também, ela não tem condições para ter a sua realização e de uma maneira natural, muito pelo contrário, já tem uma parte do caminho iniciado e ela só vai acompanhado, é um conflito já iniciado no meio social do Estado-alvo, a sua colocação é dar um suporte necessário para um movimento que estava praticando da pressão a ponto de conseguir a queda do governo vigente.

Para mostrar a ligação dos dois tópicos e de como estão um ao lado do outro, mas que acontecem em momentos diferentes, o autor destaca que

A guerra híbrida levanta a hipótese de que o conflito pré-existente em questão é uma Revolução Colorida fabricada externamente e que a Guerra Não Convencional pode ser iniciada secretamente quase que imediatamente após o início da Revolução Colorida para atuar como um multiplicador de forças. A campanha de uma Guerra Não Convencional cresce em intensidade até que o governo-alvo seja derrubado". (Korybko, 2018, p. 58).

A interação do nacional e do internacional, do interno e do externo, trazida pelo autor, anseia a uma noção de se desprender da necessidade de pensar a guerra clássica, e em vez disso considerar uma adaptação ao aumento de volume de novos atores, processos e temas em confluência no sistema internacional, a título de exemplo o surgimento de atores desvinculados do Estado e das forças especiais, como terroristas e mercenários. Além disso, o autor dá importância a um número praticamente infinito de formas pelos quais os praticantes da guerra não convencional podem proceder de maneira indireta para chegar a seus objetivos.

Ressaltando a ideia de que esses meios sempre estão ligados ao ideal liberal, a Guerra Não Convencional é uma continuação direta das Revoluções Coloridas. O autor destaca que seria uma "semente plantada", ou seja, uma forma de eco luta pelo ideal da libertação democrática, destacando que seria uma forma de manipulação da mídia ocidental.

A Guerra Não Convencional possui certas vantagens que a tornam um instrumento atraente para atingir os objetivos de política externa dos EUA. Em primeiro lugar, ela é uma estratégia para troca de regime indireta e pode ser útil contra Estados-alvo onde os EUA, por qualquer motivo que seja (político, militar, a orientação do sistema internacional etc.) não podem intervir diretamente à maneira que fizeram no Iraque em 2003, por exemplo (Korybko, 2018, p. 60)

No último capítulo "A Ponte", Korybko faz uma ligação entre as revoluções coloridas, ao tornar-se o primeiro passo da escala dos manuais de campo escritos por Gene Sharp e pelo Exército dos EUA, com táticas e orientações necessárias para 
a eventual introdução da guerra não convencional, um dos meios mais intensos e violentos, pois neste procedimento cortam-se fisicamente a conexão entre todos os elementos da sociedade. Assim, essas duas compartilham da mesma estratégia, na qual os métodos visam derrubar os governos desfavoráveis e não submissos aos EUA, fazendo destes os dois pilares da guerra híbrida.

O que faz os Estados optarem pela guerra indireta? $O$ autor, mesmo que entrelinhas, expõe os benefícios desta opção, que, dentre muitos, podemos listar: minimização de gastos; maximização de tempo e recursos; avanços tecnológicos; manutenção da ordem vigente operando o conflito apenas na economia e nas mídias, entre outros setores que são menos danosos.

Além disto, a decorrência de guerras indiretas está cada vez mais em voga, levando em consideração que os Estados em litígio preferem minimizar os danos causados em possíveis conflitos. Sendo assim, a utilização de meios não danosos (materialmente falando) é uma prioridade para os países que compreendem a ordem do sistema internacional como benéfica.

Neste sentido, a ordem vigente é importante para que muitas ações indiretas funcionem no "ataque" ao rival estabelecido. Contextualizar a ordem e agir dentro dela é umas das formas do sucesso no engajamento das ações compreendidas com a outra parte. Levar em conta este fator já deveria estar anexado às tentativas de guerra indireta empreendidas pelos Estados.

À margem deste fator determinante, estão as tentativas de guerra indireta que não levam em consideração as consequências imateriais de ações falhas. Ou seja, no litígio entre Estados não parelhos podem ocorrer ações que, de maneira indireta, não sejam benéficas para quem empreende a ação.

Um ponto relevante é perceber que se trata de uma perspectiva não-ocidental, visto que a grande maioria dos autores que estudamos tratam das regiões ocidentais. Em seu conteúdo introdutório, os Estados Unidos da América é demonizado como o principal rival que intervém em políticas internas de outros países para adquirir pontos a seu favor, porém, todo este aparato de influência tecnológico e social, não está na mão de um único país, observamos as ações chinesas e russas, que hoje contrapõem a potência norte-americana. Todos os Estados com um desenvolvimento tecnológico bem desenvolvido têm condições suficientes para agir por este meio influenciador.

A evolução tecnológica trouxe, para quase tudo, inovações e novos consensos. Para as Forças Armadas dos Estados não foi diferente, tal evolução 
proporcionou aos países e seus chefes de segurança, novos modus operandi e conceitos voltados para o soft para se ter ganhos em conflitos. Agora, o cenário de guerra deixa de ser nos campos e passa a ser nas mídias, nas notícias, utilizando as influências e o poder de convencimento sobre todo o Sistema Internacional.

A partir deste novo pensamento, podemos observar que os conflitos geopolíticos internacionais têm se desdobrado, muitas das vezes, em mídias televisivas, e na própria internet: em redes sociais, por exemplo, encontramos a participação dos chefes de Estado.

O autor explana essas mudanças no decorrer da leitura, aplicando uma metodologia eficaz e conduzindo sob as teorias mais legítimas o que pretende deixar na cabeça dos leitores. Isso deixa mais claro para nós, leitores, as novas visões sobre como se desenrolam os conflitos.

As guerras híbridas são hoje um mecanismo eficaz de maximização de benefícios e minimização de danos. Por isto, os Estados modernos detêm essa versão de guerra como preferíveis, observando o alto fluxo da globalização, onde os Estados estão em um sistema internacional mais colaborativo, para que interesses em comum sejam mais facilmente obtidos.

É válido reiterar que esta é uma visão diferente dos estudos das Relações Internacionais, afinal, este é um autor de origem russa, e não irão faltar duras críticas ao sistema de democracia liberal; pode-se levar em consideração que este é um texto pautado na perspectiva russa e, assim podemos aprender a observar como veem o que acontece a partir de outra perspectiva de mundo. As Relações Internacionais são feitos debates e discussões, a questão principal é que devemos aprender como absorver essas ideias.

Um ponto que pode ser recordado: recentemente, houve investigações nas eleições norte-americanas de interferência russa durante o processo eleitoral, e tudo isso aconteceu em um campo que não está visível "a olho nu", mas sim, observado no campo virtual e de influência indireta. Houve acusações de disseminação de Fake News que acabou favorecendo um dos lados, logo notamos este novo meio de atingir a sociedade acaba tornando-a frágil.

Outro ponto que acaba entrando em conflito com o que é discutido em grande parte das influências ocidentais para o estudo das Relações Internacionais, é na ação do que ele define como as Organizações Não-Governamentais (ONG). As ONGs constituem um mecanismo para agir para o benefício da sociedade civil, e se torna 
forte arma para a disseminação da causa de Democracia Liberal. Enquanto entendese que elas são organizações que trabalham em prol de minorias que o Estado não alcança, na perspectiva do autor ocorre justamente o contrário: as ONGs são vilãs e agem em prol de um Estado que as mantém financeiramente, e trabalham para que pessoas abracem sua causa e, logo, essas pessoas são manipuladas por uma ordem maior, sem conhecer o que seria a origem mantenedora da causa principal.

Recomendamos esta obra para o leitor questionar e refletir sobre a temática das guerras híbridas, um fenômeno recente e cujas construções poderão agregar diante dos tópicos aqui citados. As análises concebidas por Andrew Korybko oferecem ao leitor uma ampla compreensão dos estímulos de diferentes atores da sociedade, e algumas questões relevantes para serem consideradas à luz do momento histórico atual. Faz-se necessário um conhecimento preliminar acerca das linhas gerais do tema tratado.

\section{Referências bibliográficas}

KORYBKO, Andrew. Guerras híbridas - das revoluções coloridas aos golpes. São Paulo: Expressão Popular, 2018. 